\title{
Nutritional Status by Using Selected Anthropometric Parameters of Under Five Children from the Selected Urban Slums in Pune City
}

\author{
Prof. Sreelekha Rajesh ${ }^{1}$, Prof. (Dr.) Mahipal Singh ${ }^{2 *}$
}

${ }^{1}$ Vice Principal, GMF's, Tehmi Grant Institute of Nursing Education, Pune, Maharashtra, India

${ }^{2}$ Principal Akhil Bharati Vidyapeeth College of Nursing, Sikar Rajasthan, India

DOI: $10.36347 /$ sjams.2020.v08i08.014

| Received: 01.08.2020 | Accepted: 18.08.2020 | Published: 22.08.2020

*Corresponding author: Dr. Mahipal Singh

\section{Abstract}

Original Research Article

India secures a second position worldwide followed by Bangladesh in the year 1998. It accounts that $47 \%$ of the children possess a degree of malnutrition as per the estimation given by World Bank. In the world, India shows the highest ratio of underweight children in terms of mortality, productivity and economic growth. The main objective of this study is to assess the nutritional status among fewer than five children and to compare it with the selected demographic variables. The study is supported by modified health belief model. A structured interview schedule was used to determine the demographic data and anthropometric parameters of fewer than five children. Non Experimental uni-variant descriptive design is used, enrolling 100 under five children. The technique used in the study is Non probability convenient sampling technique and it shows that out of 100 under five children $67 \%$ are malnourished and $33 \%$ are well nourished respectively.

Keywords: Nutritional status, Anthropometric parameters, Malnutrition, Under five children.

Copyright @ 2020: This is an open-access article distributed under the terms of the Creative Commons Attribution license which permits unrestricted use, distribution, and reproduction in any medium for non-commercial use (NonCommercial, or CC-BY-NC) provided the original author and source are credited.

\section{INTRODUCTION}

India is one among the fastest growing countries in terms of economics and inhabitants, posing at a population of 1,139.96 million (2009) and growing at $10-14 \%$ annually (from 2001-2007). India's Gross Domestic Product growth was $9.0 \%$ from 2007 to 2008; since 1947 during Independence period, its economic status has been categorized as a low-income country with major population below the poverty line. This explains that most of the people are still living below the National Poverty Line; malnutrition refers to the situation where there is an unbalanced diet in which some nutrients are in excess, deficient or inadequate. Gender inequality is the most significant reason for malnutrition in India. Due to the low social status of Indian women, their diet often lacks in both quality and quantity. Women who are undernourished are more likely to have unhealthy babies. The knowledge among the Indian mothers regarding feeding their children is insufficient. Thus, new born infants are unable to get adequate amount of nutrition from their mothers.

\section{Need of the Study}

Malnutrition is increasing worldwide, which leads to worrying implications for short-term survival and longer-term well-being, economic growth, and socioeconomic inequality. The National Family Health
Survey (NFHS:3, 2005-6) states that approximately 5.2 crores children are undersized (height for age standard deviation $[\mathrm{z}]$ score $<-2)$. In comparison, rural children are more malnourished than urban. Furthermore, it describes stunting as $40 \%$, where wasting accounts $17 \%$ (weight for height $\mathrm{z}$ score $<-2 \mathrm{SD}$ ) and $33 \%$ is low weight for their age $(<-2 \mathrm{SD})$ in urban children under five. In the same survey, $47 \%$ of children from Mumbai slum areas were stunted which represents $16 \%$ wasted and $36 \%$ were underweight as per their age. Where trans-generational, environmental and dietary factors are considered to play an important role. There are questions about the underlying dynamics of nutrition, related to its significant increase in the gross national income per capita and concerns about its inequalities. During a survey conducted in the urban slum area it was found that many under five children were malnourished. Thus, it's important to group these children according to the grades of malnutrition. This will simplify the need to identify children who should receive benefits from the community based nutritional interventional program. Using the child growth standards formulated by WHO in 2006 it is expected that many children will be found to have an unsteady growth. Thus, it is essential to assess the nutritional status of fewer than five children with the use of selected anthropometric parameters. 


\section{Problem Statement}

Nutritional status by using selected anthropometric parameters in selected urban slum areas in Pune City. Objectives of study are, to assess nutritional status among fewer than five children and to correlate nutritional status with the selected demographic variables.

\section{REVIEW OF LITERATURE}

\section{Section I: Literature Review Related To Nutritional Status of Children}

Thomas R et al. [1] has conducted a study to assess the Nutritional Status of Tribal Children and Adolescents in Rural South India. The main objective of the study was to investigate the prevalence of malnutrition using anthropometric measures in a cohort of tribal students attending a school in rural south India. Children attending the school were 3 meals a day were offered. Analysis of anthropometric data obtained aimed to determine the nutritional effect of the food provided. The assessment was done of nutritional status of 409 students by comparing anthropometric measurements to reference values.

It was found that the prevalence of thinness of new students was $39.4 \% .59 .5 \%$ and that of old was $52.9 \% .59 .4 \%$ of students were classified as stunted. $73.8 \%$ of 'new' students and $52.9 \%$ of 'old' students demonstrated stunting (P 0.091). Significantly (P 0.010) it was noted that more 'new' female students had stunted growth. Thus, the acute and chronic measures of malnutrition were highest among the adolescent students attending the school.

Amrutha et al. [2]. A study aimed to evaluate the nutritional status of infants in Ramanathapuram district of Tamil Nadu. The present study comprised a community based cross sectional study conducted in 7 talukas. A total of 2800 infants $(<1 \mathrm{yr}$ of age $)$ comprising of 1400 male and female infants respectively were randomly selected from 7 talukas. Anthropometric parameters such as weight, crown heel length, head circumference, arm circumference and chest circumference were measured using standardised procedures. Clinical examinations for the manifestation of micronutrient deficiency signs were performed. Biochemical estimations of serum haemoglobin, vitamin A and urinary iodine were estimated for 5\% of the infants.

A result shows that Low birth weight was observed among $33.5 \%$ of the infants, with $1.6 \%$ weighing $<1500 \mathrm{~g}$. being underweight $(35.4 \%)$, stunting $(29.6 \%)$ and wasting (18.9\%) were also observed among the infants. Different forms of clinical signs and symptoms of micronutrient deficiencies were observed among $21.3 \%$ and $27.4 \%$ of the male and female infants. Sub-clinical deficiency of hemoglobin, vitamin $\mathrm{A}$ and iodine were observed among $67.1 \%, 52.1 \%$ and $32.9 \%$ of the infants, respectively.

\section{Section I: Literature Review Related To} Effectiveness of Anthropometric Parameters

Haifa Tawfeek et al. [3] Anthropometric measurements were obtained in 3,616 children of under five years of age. Among those children, 24\% were diagnosed as moderately undernourished and $6 \%$ as severely undernourished by mid upper arm circumference measurements. The anthropometric indices used to identify malnutrition were weight for age, weight for height and height for age $\mathrm{Z}$ scores. Each of the anthropometric index was categorized as mild (-1 to -2 SID), moderate $(-2$ to -3 SID), or severe $(<-3$ SD) [14 According to weight-for-height, only $11 \%$ were diagnosed as moderately undernourished and 3\% as severely undernourished. The inconsistency between the results of these two measurements can be minimized by establishing a new cut-off level for mid-upper-arm circumference for defining malnutrition in our population.

Khan A Z et al. [4] Anthropometric parameters were measured of 1012 rural school-going children, selected randomly. There were 776 males and 236 females in the age group of 5-15 years. The parameters of weight and height were recorded for every child. Age and sex break-up was studied and compared with the Indian Council of Medical Research standard. The comparison made separately for boys and girls showed that the values for both sex in all age groups were less in comparison to the standards given by Indian Council of Medical Research. The majority $(83.6 \%)$ of the children belonged to the middle and low social class according to the modified Prasad's classification. Physical growth, in terms of weight and height, is considered an important parameter reflecting the pattern of growth and development in a community, this nutritional deficiency results in relative stunting of growth.

\section{Materials And Methods Research Approach}

The main aim of this study is to assess nutritional status by using selected anthropometric parameters of under five children in order to achieve the objectives of this study, the method adopted was descriptive approach. Research design adopted is Non experimental uni-variant descriptive design in urban slum areas of Pune city. Study was conducted from august 2019 to nov.2019 on 100 samples less than five years of children residing in urban slums. Samples were selected by Non Probability convenient sampling.

\section{Data Analysis \& Results}

The collected data is tabulated, analyzed, organized and presented under the following headings:

Section I: Analysis of demographic data of the mothers of under five children. This section includes distribution 
of subjects in relation to demographic data using frequency and percentage.

Section II: Analysis of data related to nutritional status of under five children.

Section III: Analysis of data to find the association of nutritional status of under five children with selected demographic variables.
The analysis of the collected data was done with the help of inferential and descriptive statistics. The data is then processed by using Chi square. A ' $p$ ' value less than 0.05 was considered as significant. Descriptive statistics in the form of calculation of mean and standard deviation was utilized to analyze the demographic variables.

\section{Section i: analysis of demographic data}

Table-4.1.1: Socio-demographic data of mother

\begin{tabular}{|c|c|c|c|}
\hline \multicolumn{2}{|l|}{ Parameters } & No of cases & Percentage $(n=100)$ \\
\hline \multirow{4}{*}{ Age of mother (Yrs) } & $<20$ & 5 & 5 \\
\hline & $21-30$ & 88 & 88 \\
\hline & $31-40$ & 5 & 5 \\
\hline & $>40$ & 2 & 2 \\
\hline \multirow{2}{*}{ Under five children } & $1-2$ & 97 & 97 \\
\hline & $3-4$ & 3 & 3 \\
\hline \multirow{4}{*}{ Education } & Primary & 45 & 45 \\
\hline & Secondary & 35 & 35 \\
\hline & Higher secondary & 13 & 13 \\
\hline & Graduate \& above & 7 & 7 \\
\hline \multirow{2}{*}{ Occupation } & Employed & 42 & 42 \\
\hline & Housewife & 58 & 58 \\
\hline \multirow{2}{*}{ Type of family } & Joint & 38 & 38 \\
\hline & Nuclear & 62 & 62 \\
\hline \multirow{4}{*}{ Monthly income } & $<5000$ & 27 & 27 \\
\hline & $5001-10000$ & 49 & 49 \\
\hline & $10001-15000$ & 7 & 7 \\
\hline & $>15000$ & 17 & 17 \\
\hline
\end{tabular}

\section{MAJOR FINDINGS OF STUDY}

Section I: Analysis of the demographic data of mothers of under five children

- Illustrates mothers belonging to the less than or equal to 20 are $5 \%$; the maximum i.e. $88 \%$ belongs to the age group between $21-30$ years. And 5\% belongs to the age group 31- 40 years while only $2 \%$ mothers belong to more than 40 years

- Majority (97\%) of the families have 1-2 under five children and $3 \%$ of the families have 3-4 under five children.

- Majority of mothers (45\%) have studied up to primary; $35 \%$ have studied up to secondary while
$13 \%$ have higher secondary education. Only $7 \%$ have acquired graduation and above

- Majority of the mothers i.e. 58\% are housewives while $42 \%$ are employed.

- Most of mothers (62\%) are from nuclear family and $38 \%$ are from joint family.

- The family income of $49 \%$ mothers is Rs. 5001$10000,27 \%$ have a monthly family income of less than Rs. 5000. Whereas $17 \%$ mothers have a monthly family income of more than Rs.15000/-; only $7 \%$ have a family income of more than Rs.10001 - 15000.

Section ii: analysis of data related to the nutritional status of fewer than five children

Table-4.2 (a): Nutritional status wise distribution of children in study group

\begin{tabular}{|l|l|l|}
\hline Nutritional status & No. of children & Percentage \\
\hline No. of malnourished children & 67 & 67 \\
\hline No. of non - malnourished children & 33 & 33 \\
\hline Total & 100 & 100 \\
\hline
\end{tabular}




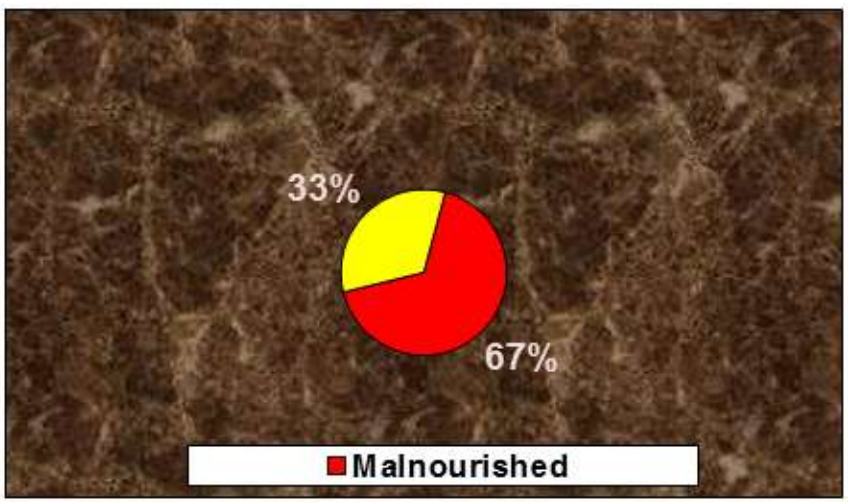

Graph-4.2 (a): Pie diagram shows the distribution of under five children based on their nutritional status (n=10)

Graph 4.2 (b) States that out of 100 under five children $67 \%$ children are malnourished and 33\% children are non malnourished.

Table-4.2 (b): Distribution of fewer than five children based on grades of malnutrition

\begin{tabular}{|l|l|l|}
\hline Grades of malnutrition & No. of children & Percentage \\
\hline Mild & 33 & 33 \\
\hline Moderate & 25 & 25 \\
\hline Severe & 9 & 9 \\
\hline Normal & 33 & 33 \\
\hline Total & 100 & 100 \\
\hline
\end{tabular}

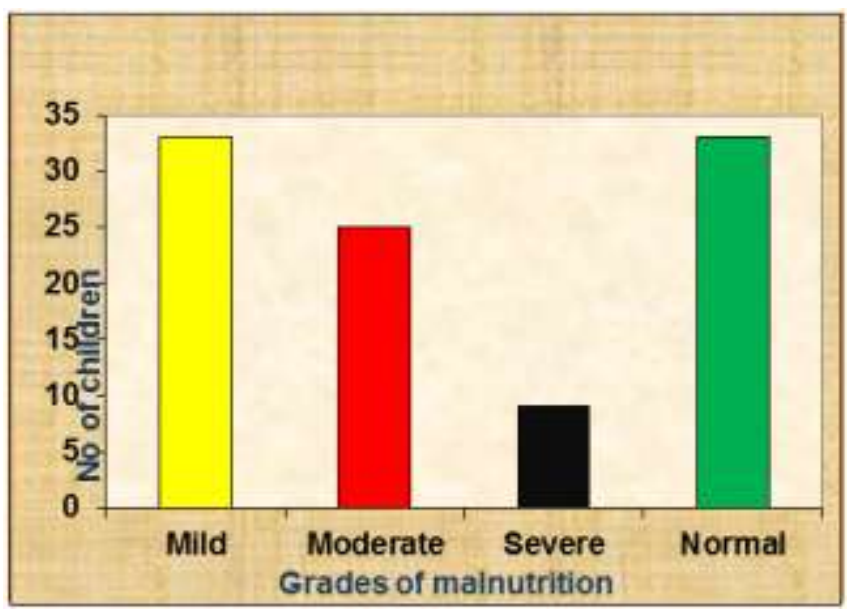

Graph-4.2 (b): Bar diagram shows grades of malnutrition among under five children ( $n=100)$

Graph 4.2 (b) Shows the grades of malnutrition; 33\% children are having mild malnutrition, $25 \%$ children are having moderate malnutrition and $9 \%$ children are having severe malnutrition

Section iii: the association of nutritional status of fewer than five children with selected demographic variables.

Table-4.3 (a): Association between age and nutritional status in study group

\begin{tabular}{|l|l|l|l|}
\hline \multirow{2}{*}{ Age (Yrs) } & \multicolumn{2}{|l|}{ Nutritional status } & \multirow{2}{*}{ Total } \\
\cline { 2 - 3 } & Malnourished & Non- malnourished & \\
\hline$<20$ & 4 & 1 & 5 \\
\hline $21-30$ & 59 & 29 & 88 \\
\hline$>30$ & 4 & 3 & 7 \\
\hline Total & $\mathbf{6 7}$ & $\mathbf{3 3}$ & $\mathbf{1 0 0}$ \\
\hline
\end{tabular}

Chi-square $=0.75, \mathrm{P}>0.05$

Graph 4.3 (a) shows there is a significant association between nutritional status of the fewer than five children and age of mother at 0.05 level of significance. 
Table-4.3 (b): Association between less than five children and nutritional status in study group

\begin{tabular}{|l|l|l|l|}
\hline \multirow{2}{*}{ No. of under five children } & \multicolumn{2}{|l|}{ Nutritional status } & Total \\
\cline { 2 - 3 } & Malnourished & Non- Malnourished & \\
\hline $1-2$ & 65 & 32 & 97 \\
\hline $3-4$ & 2 & 1 & 3 \\
\hline Total & 67 & 33 & 100 \\
\hline
\end{tabular}

Chi-square $=0, \mathrm{P}>0.05$

Graph 4.3 (b) shows there is no association between nutritional status of fewer than five children and the number of fewer than five children in the family at 0.05 level of significance.

Table-4.3 (c): The association between education and the nutritional status

\begin{tabular}{|l|l|l|l|}
\hline \multirow{2}{*}{ Education } & \multicolumn{2}{|l|}{ Nutritional status } & \multirow{2}{*}{ Total } \\
\cline { 2 - 3 } & Malnourished & Non- malnourished & \\
\hline Primary & 30 & 15 & 45 \\
\hline Secondary & 24 & 11 & 35 \\
\hline Higher secondary & 7 & 6 & 13 \\
\hline Graduate \& above & 6 & 1 & 7 \\
\hline Total & 67 & 33 & 100 \\
\hline
\end{tabular}

Chi-square $=2.17, \mathrm{P}>0.05$

Table 4.3 (c) shows there is a significant association between the nutritional status of under five children and education of mother at 0.05 level of significance.

Table-4.3 (d): Association between occupation and nutritional status

\begin{tabular}{|l|c|c|c|}
\hline \multirow{2}{*}{ Occupation } & Nutritional status & Total \\
\cline { 2 - 3 } & Malnourished & Non - Malnourished & \\
\hline Employee & 29 & 13 & 42 \\
\hline Housewife & 38 & 20 & 58 \\
\hline Total & 67 & 33 & 100 \\
\hline
\end{tabular}

Table 4.3 (d) shows there is a significant association between the nutritional status of under five children and occupation of mother at 0.05 level of significance.

Table-4.3 (e): The association between the type of family and their nutritional status

\begin{tabular}{|l|l|l|l|}
\hline \multirow{2}{*}{ Type of family } & \multicolumn{2}{|l|}{ Nutritional status } & \multirow{2}{*}{ Total } \\
\cline { 2 - 3 } & Malnourished & Non- Malnourished & \\
\hline Joint & 26 & 12 & 38 \\
\hline Nuclear & 41 & 21 & 62 \\
\hline Total & 67 & 33 & 100 \\
\hline
\end{tabular}

Chi-square $=0.06, \mathrm{P}>0.05$

Table 4.3 (e) shows there is a significant association between nutritional status of the under five children and the type of family at 0.05 level of significance

Table-4.3 (f): Association between total family income and nutritional status

\begin{tabular}{|l|l|l|l|}
\hline \multirow{2}{*}{ Total family income } & Nutritional status & \multirow{2}{*}{ Total } \\
\cline { 2 - 3 } & Malnourished & Non- Malnourished & \\
\hline$<5000$ & 17 & 10 & 27 \\
\hline $5001-10000$ & 35 & 14 & 49 \\
\hline $10001-15000$ & 4 & 3 & 7 \\
\hline$>15000$ & 11 & 6 & 17 \\
\hline Total & 67 & 33 & 100 \\
\hline
\end{tabular}

Table 4.3 (f) states that there is significant association between nutritional status of under five children and their total family income at 0.05 level of significance. 
Table-4.3 (g): Association between age of child and their nutritional status

\begin{tabular}{|l|c|c|c|}
\hline \multirow{2}{*}{ Age of child } & \multicolumn{2}{|c|}{ Nutritional status } & Total \\
\cline { 2 - 3 } & Malnourished & Non- Malnourished & \\
\hline$<1$ & 11 & 2 & 13 \\
\hline $1-3$ & 46 & 20 & 66 \\
\hline$>3$ & 10 & 11 & 21 \\
\hline Total & 67 & 33 & 100 \\
\hline
\end{tabular}

Chi-square $=5.61, \mathrm{P}>0.05$

Table $4.3(\mathrm{~g})$ : shows there is a significant association between nutritional status of the under five children and their age at 0.05 level of significance.

Table-4.3 (h): Association between gender of child and their nutritional status

\begin{tabular}{|l|l|l|l|}
\hline \multirow{2}{*}{ Sex of child } & Nutritional status & \multirow{2}{*}{ Total } \\
\cline { 2 - 3 } & Malnourished & Non- Malnourished & \\
\hline Male & 34 & 20 & 54 \\
\hline Female & 33 & 13 & 46 \\
\hline Total & 67 & 33 & 100 \\
\hline \multicolumn{3}{|c|}{ Chi-square $=0.87, \mathrm{P}>0.05$} \\
\end{tabular}

Table 4.3 (h) shows there is a significant association between the nutritional status of fewer than five children and their gender at 0.05 level of significance.

Table-4.3 (i): Association between birth weight and nutritional status

\begin{tabular}{|l|l|l|l|}
\hline \multirow{2}{*}{ Birth weight } & Nutritional status & \multirow{2}{*}{ Total } \\
\cline { 2 - 4 } & Malnourished & Non - Malnourished & \\
\hline$<1.5$ & 13 & 8 & 21 \\
\hline $1.5-2.5$ & 40 & 18 & 58 \\
\hline $2.5-3.5$ & 11 & 5 & 16 \\
\hline$>3.5$ & 3 & 2 & 5 \\
\hline Total & 67 & 33 & 100 \\
\hline \multicolumn{3}{|c|}{ Chi-square $=0.48, \mathrm{P}>0.05$} \\
\hline
\end{tabular}

Table 4.3 (i) shows there is a significant association between the nutritional status of under five children and their birth weight at 0.05 level of significance.

\section{LIMITATION OF THE STUDY}

- The study is limited to the under five children.

- Non Probability convenient sampling technique is used.

- Only a certain parameter is used to assess the nutritional status of the chidren.

\section{Conclusion}

The study concludes that fewer than five children residing in selected urban slums are not maintaining proper nutritional status. The data analysis is done with the help of inferential and descriptive statistics. The data is further processed by using Chi square. A ' $p$ ' value less than 0.05 was considered as significant. Descriptive statistics in the form of calculation of mean and standard deviation was utilized to analyze the demographic variables. Among 100 under five children $67 \%$ of children are malnourished and $33 \%$ children are well nourished. Among 100 under five children $33 \%$ of children are come in grades of mild malnutrition, $25 \%$ are come under moderate malnutrition, $9 \%$ are come under severe malnutrition and $33 \%$ are come under normal nutritional status.
There is a considerable association between nutritional status of the under five children at 0.05 level of significance with selected demographic variables i.e. age of the mother, education of mother, occupation of mother, type of family, total family income, age of the child, gender and birth weight. Health care workers need to give more attention to children to get community based nutritional interventional program.

\section{REFERENCES}

1. Prentice AM, Ward KA, Goldberg GR, Jarjou LM, Moore SE, Fulford AJ, Prentice A. Critical windows for nutritional interventions against stunting. Am J Clin Nutr. 2013 May; 97(5):911-8.

2. Patil S, Rao RS, Sanketh DS, Amrutha N. Microbial flora in oral diseases. The journal of contemporary dental practice. 2013 Nov $1 ; 14(6): 1202$.

3. Tawfeek H, Al-Mashikhi SA, Salom A. The Iraqi national nutrition survey: Correlation between various anthropometric measurements as indicators of severity of malnutrition. Food and nutrition bulletin. 1998 Dec;19(4):318-20.

4. Khan AZ, Singh NI, Hasan SB, Sinha SN, Zaheer M. Anthropometric measurements in rural school children. Journal of the Royal Society of Health. 1990 Oct;110(5):184-6. 